\title{
Fetal Lower Urinary Tract Obstruction: An Update
}

\author{
Russell S. Miller*
}

\author{
Carmen and John Thain Center for Prenatal Pediatrics, Division of Maternal Fetal Medicine, Department of Obstetrics \\ and Gynecology, Columbia University Medical Center, New York, NY, USA
}

\begin{abstract}
Fetal lower urinary tract obstruction [LUTO] represents a rare, heterogeneous group of uropathies involving mechanical or functional blockage at the bladder outlet of varying severity. While ultrasound is a fair screening tool for the antenatal detection of this condition, it cannot reliably determine the underlying etiology of LUTO presentations. Sonographic assessment of renal appearance and amniotic fluid volume, as well as urinary analyte analysis, are the most useful predictors of preserved renal function in fetal LUTO, although they, too, are limited in their ability to predict outcomes on an individual basis. Animal models suggest that obstructive uropathy likely causes irreparable damage to the renal and urinary collecting system injury early in pregnancy. When LUTO is associated with abnormal amniotic fluid volume, long-standing oligohydramnios may result in lethal pulmonary hypoplasia. Data evaluating the efficacy of vesicoamniotic shunt therapy for the treatment of fetal LUTO are inconclusive. While vesicoamniotic shunting may modify disease lethality by restoring fluid volume, renal and other genitourinary benefits are minimal if not altogether absent, arguably supporting the belief that bladder decompression is being performed after irreversible injury has already been sustained.
\end{abstract}

Keywords: Fetal urinary tract obstruction, oligohydramnios, prenatal diagnosis, prenatal ultrasonography, posterior urethral valves, urinary analytes, vesicoamniotic shunt.

\section{INTRODUCTION}

Fetal lower urinary tract obstruction [LUTO], or bladder outlet obstruction, is a rare, heterogeneous group of uropathies where mechanical or functional blockage at the level of the urethra limits or altogether prevents urination from the bladder to the amniotic space. In severe forms, the resultant urinary retention leads to abnormal pressurization that is deleterious to the developing fetal kidneys and urinary tract, as well as oligo- or anhydramnios that can cause potentially life-threatening pulmonary hypoplasia. The condition is associated with high rates of perinatal mortality and, among survivors, long-term morbidity. Fetal therapy intended to functionally bypass the level of urinary obstruction exists for severe LUTO presentations associated with oligohydramnios. While this treatment appears to confer survival benefits by limiting oligohydramnios and related pulmonary hypoplasia, similar therapeutic renal and urinary tract benefits are unproven.

\section{EPIDEMIOLOGY}

The reported incidence of LUTO varies within published literature, likely attributable to a range of disease severity, differences in antenatal detection rates, and populationsampling methodology employed. The incidence widely ranges from $1: 2,000$ to $1: 25,000$ live births [1-4]. Whereas

*Address correspondence to this author at the Division of Maternal Fetal Medicine, Department of Obstetrics and Gynecology, Columbia University Medical Center, 622 West 168th Street, PH 16-66, New York, New York 10032, USA; Tel: (212) 305-6293; Fax: (212) 342-2717;

E-mail:rsm20@columbia.edu older literature suggested that posterior urethral valves [PUV], the most common cause for LUTO presentations, represented $10 \%$ of live-born neonates with prenatally diagnosed uropathies, much recent data suggests that this incidence may be closer to $1 \%[5,6]$.

In a population-based study of prenatal diagnostic accuracy trends within the northern UK during years 1985 through 2000, bladder outlet obstruction had an overall prevalence of approximately 1.8 per 10,000 births [7]. Prenatal diagnosis was achieved in $42 \%$ of cases at the beginning of the study [1985-1988] and 69\% by the end of the observation period [1997-2000]. In another retrospective population-based study sampling from the West Midlands between 1995 and 2007, there was a total prevalence of 3.3 per 10,000 births that remained essentially stable over time [8]. $77.8 \%$ of cases were isolated, with the remaining being complex presentations. Overall prenatal detection was $50.7 \%$, with a higher detection rate of $57.1 \%$ in complex cases when compared to $48.9 \%$ in isolated cases. LUTO prevalence was higher in Black and unselected minority groups [6.3 per 10,000 births] when compared to white European pregnancies [2.6 per 10,000 births]. An association with socioeconomic deprivation was also observed.

\section{ETIOLOGY}

LUTO predominantly affects male fetuses [3, 8]. Contemporary UK data indicate that the most common LUTO subtypes are PUV [63\%], urethral atresia [9.9\%], urethral stenosis [7.0\%], and prune belly syndrome [2.5\%], with unspecified etiology accounted to $17.6 \%$ of cases [8]. Female LUTO cases are extremely rare, and usually involve 
urethral atresia, cloacal dysgenesis, or megacystis microcolon intestinal hypoperistalsis syndrome [MMIHS].

Nearly $80 \%$ of prenatally detected LUTO cases are isolated, and for these fetuses PUV remains the majority subtype [8]. Among complex cases with additional anomalies, LUTO is due to PUV, urethral atresia, and unspecified etiologies in nearly equal distribution. Anatomically, PUVs are abnormal membranous structures located between the verumontanum of the prostatic urethra and the external urethral sphincter [2]. In 1919, Young classified the condition into three types based upon anatomical location and presumed underlying developmental abnormality [9]. This classification system remains in clinical use today.

Prune belly syndrome, also known as Eagle-Barrett syndrome, is a pediatric diagnosis defined by a triad of findings: deficient or absent abdominal wall musculature resulting in a flaccid, wrinkled neonatal abdomen; urinary tract obstruction; and bilateral cryptorchidism [10, 11]. The pathogenesis of this condition is not well understood. Antenatally, it can be very difficult to distinguish between prune belly syndrome and other conditions presenting with LUTO.

MMIHS is a rare genetic syndrome with antenatal presentation often including megacystis [often without "keyhole" appearance], associated genitourinary findings, and gastrointestinal abnormalities such as dilated stomach or bowel loops [12]. The condition is inherited as autosomal recessive, and so antenatal diagnosis may be suspected in the context of a suggestive family history. The condition is associated with significant pediatric morbidity and mortality, and prenatal vesicoamniotic shunt therapy is not of proven benefit for this condition. Therefore, it is important to distinguish MMIHS from other causes LUTO when possible.

Congenital megalourethra is a rare cause of functional LUTO due to a deficiency or absence of the mesodermal tissues of the penis [13]. This deficiency results in urinary stasis within the penile urethra and a resultant massively dilated, skin-covered penis. There are two main types of congenital megalourethra: the scaphoid type, in which there is complete or partial deficiency of the corpus spongiosum; and the fusiform type, in which all penile bodies [corpora cavernosa and corpus spongiosum] are deficient. Fusiform types are associated with higher rates of associated malformations and mortality $[14,15]$. When detected antenatally, there is no evidence to support improved outcomes for functional megalourethra cases when compared to mechanical LUTO presentations [16]. Survivors are at risk to experience dysfunction with urination and issues with erection and ejaculation.

Fetal aneuploidy ranges from $5-12 \%$ of prenatal LUTO cases, with reported abnormalities including trisomies 21 , 18, and 13, as well as 47, XXY [17-20]. Aneuploidy rate appears to be disproportionately higher among complex LUTO presentations, at roughly $25 \%$ of complex cases with known karyotype [8]. There is a lack of published microarray or whole exome sequencing data for pregnancies complicated by LUTO.

\section{NATURAL HISTORY}

Without treatment, LUTO has been associated with a $45 \%$ mortality rate, largely attributable to pulmonary hypoplasia [21]. In untreated cases complicated by early second-trimester oligohydramnios, in which case pulmonary hypoplasia is largely unavoidable, mortality approaches $95 \%$ [22]. Beyond mortality risk, long-standing oligohydramnios places survivors at risk for Potter's facies, skeletal deformities, poor growth, limb contractures, and scoliosis.

Pediatric LUTO survivors are at high risk for renal insufficiency, end-stage renal disease [ESRD], and renal transplantation due to pressure-induced injury to the developing fetal kidney. Patients with PUV have an estimated $28.5 \%$ lifetime risk of developing ESRD, with roughly two-thirds of cases occurring by age 17 [23]. National transplant registry data published in 2006 indicated that among patients undergoing transplantation for ESRD, $15.8 \%$ were attributed to "obstructive uropathy", and an additional $2.7 \%$ to prune belly syndrome [24].

Other structures along the genitourinary tract are similarly compromised in antenatal LUTO presentations [25]. Pediatric survivors are at high risk to experience poor bladder compliance and detrusor overactivity, and adults commonly possess oversized bladders with incomplete emptying. Urinary incontinence is a frequent problem most commonly, nocturnal enuresis. Intermittent catheterizations are frequently required, and urinary tract infections are common. Affected children are at increased risk for requiring urological procedures, often related to the underlying etiology for the obstruction. Sexual dysfunction, infertility, and cryptorchdisim are also potential concerns within this population.

Lamb models indicate that the proximal tubules and nephrogenic zone are the first areas of the fetal kidney to sustain damage in the setting of obstructive uropathy, and that progressive pathological changes are evident by 48 hours after obstruction [26]. While shunting performed 21 days after obstruction in these models can prevent fetal development of renal cystic dysplasia, oligonephronia or multicystic dysplastic changes are noted in $45 \%$ of subjects [27]. Bladders are consistently hypertrophied with small compliance, indicating that shunting fails to preserve bladder function. Studies indicate that changes in bladder wall and thickness is evident within four to seven days of obstruction [28]. Structural and functional ureteral changes have also been demonstrated in animal models of obstructive uropathy [29]. Kitajima and colleagues have noted that the timing of intervention in lamb models of obstructive uropathy would correlate with a human equivalent of roughly 15 to 17 weeks of gestational age, which is earlier than shunts that are generally placed in clinical practice [27]. Therefore, animal data suggest that shunt decompression at more advanced gestational ages is unlikely to substantially prevent or reverse the severe LUTO genitourinary phenotype.

\section{PRENATAL SONOGRAPHIC DIAGNOSIS}

In large population studies, including those listed above, antenatal detection of LUTO occurs in roughly $50 \%$ to $70 \%$ 
of cases $[7,8,30]$. In the EUROSCAN Study Group analysis of prenatal detection of congenital renal malformations, 27 cases of PUV occurred among 709,030 births across 12 European countries [30]. 19 were detected antenatally, yielding a $70.4 \%$ detection rate. Mean gestational age at diagnosis was 22.7 weeks, with a range from 12 to 36 weeks. Among prenatally diagnosed cases, initial detection was under 18 weeks in five cases [26.3\%], and between 18 and 24 weeks in eight [42.1\%].
Prenatal diagnosis of LUTO involves detection of a thick-walled, dilated bladder, usually with a dilated proximal [posterior] urethra in characteristic "keyhole" appearance (Figs. 1, 2). The bladder can become markedly enlarged with complete obstruction occupying the fetal pelvis and abdomen, and fail to empty. Mural thickness greater than 2 $\mathrm{mm}$ is considered to be pathological, and LUTO bladders can greatly exceed this threshold (Figs. 3-5).

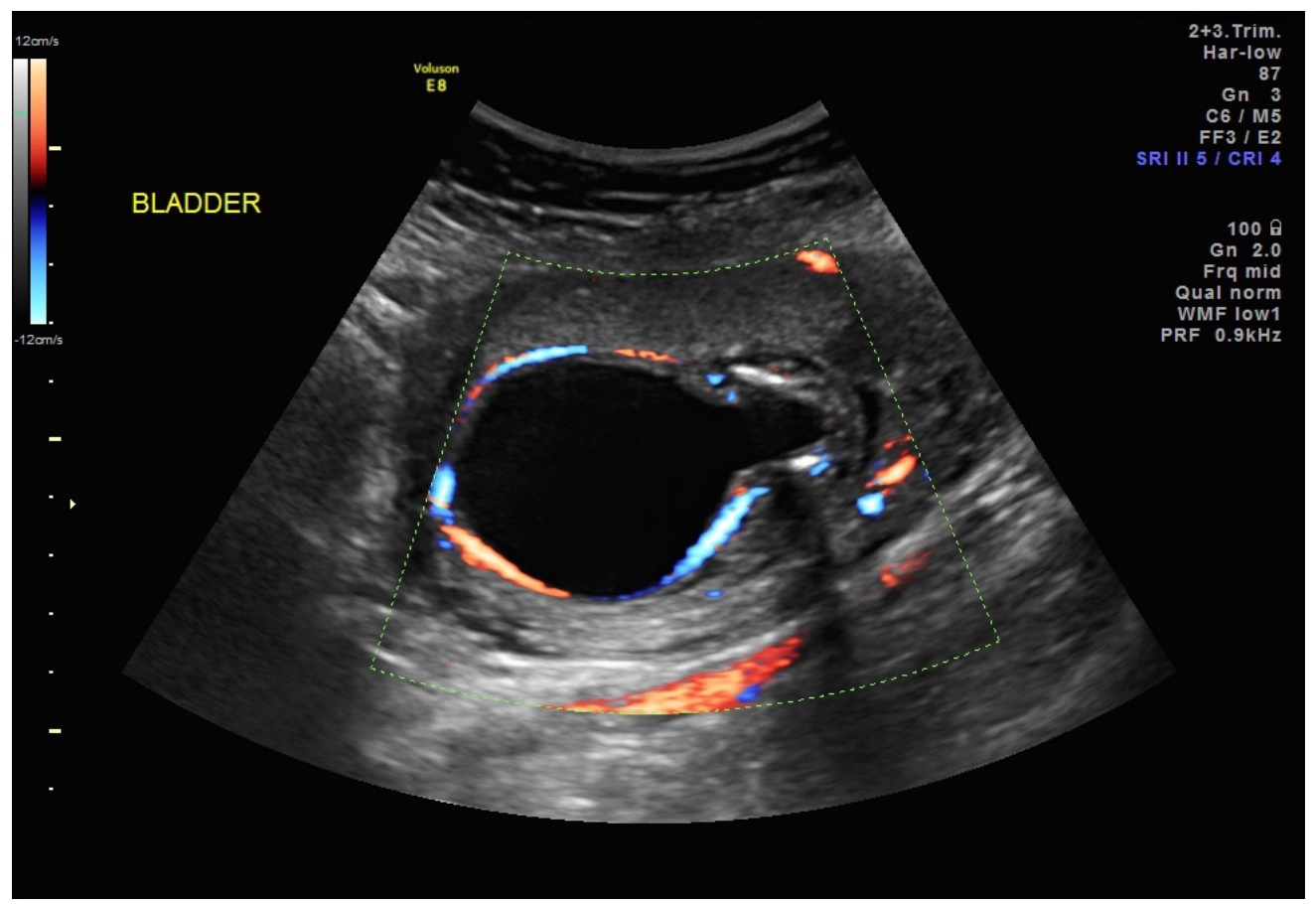

Fig. (1). "Keyhole" bladder. Axial view of a distended fetal bladder in an 18-week fetus with anhydramnios. Color Doppler study demonstrates umbilical arteries.

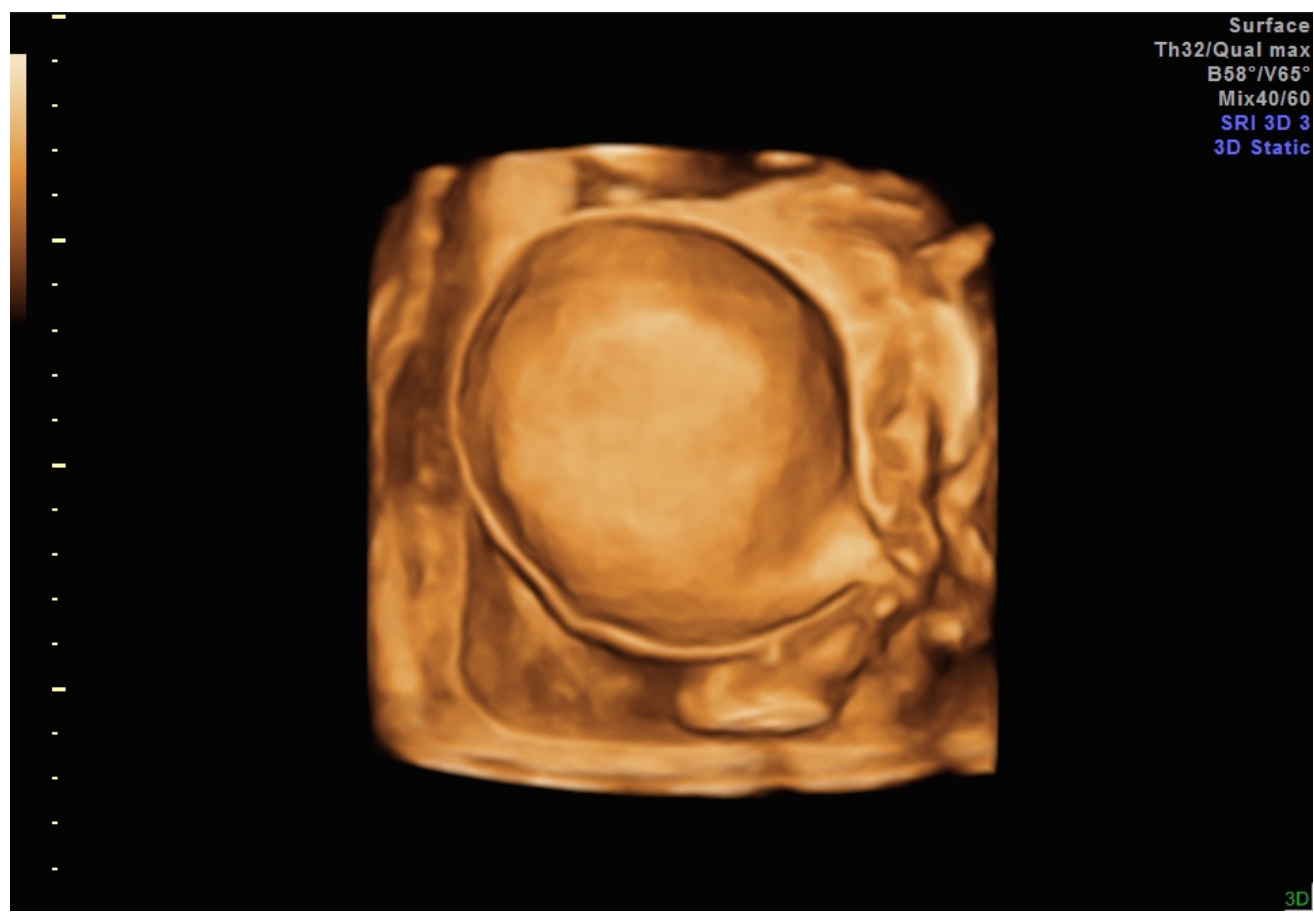

Fig. (2). "Keyhole" bladder. 3D rendering of distended bladder in a 19-week fetus, sagittal view. 


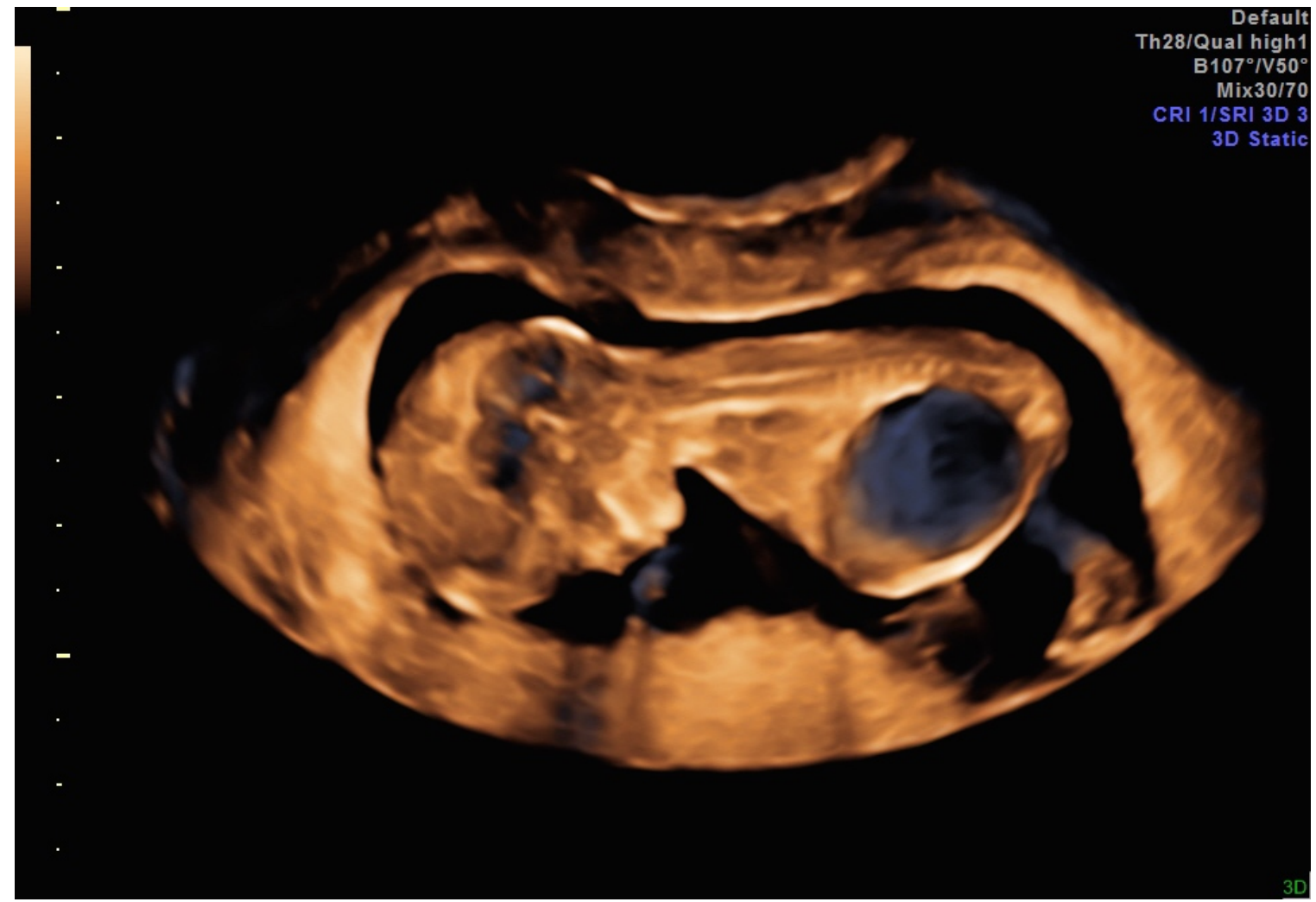

Fig. (3). Megacystis in a 12-week fetus, sagittal view. Subsequent LUTO diagnosis.

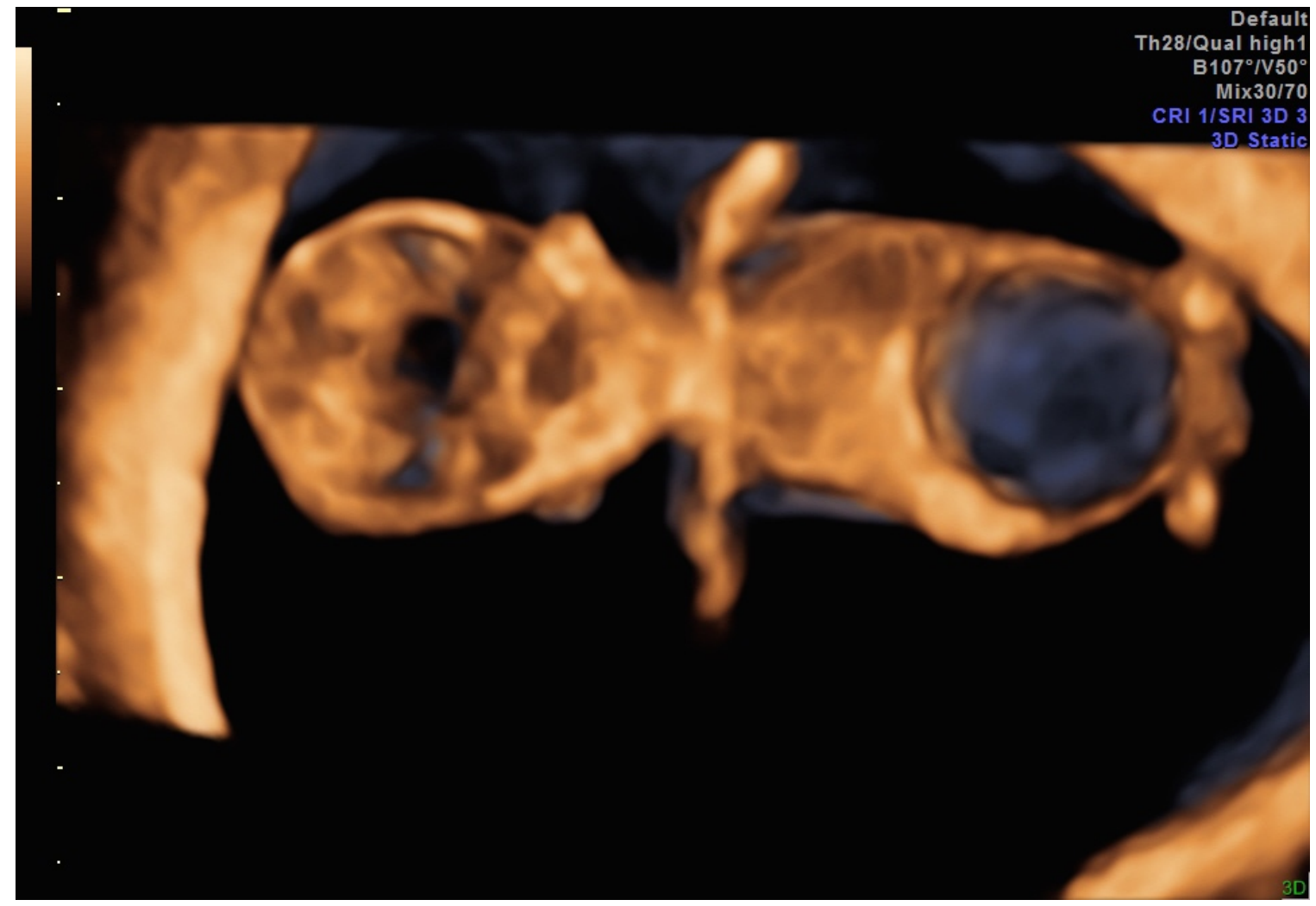

Fig. (4). Megacystis in the same 12-week fetus as Fig. (3), coronal view. 


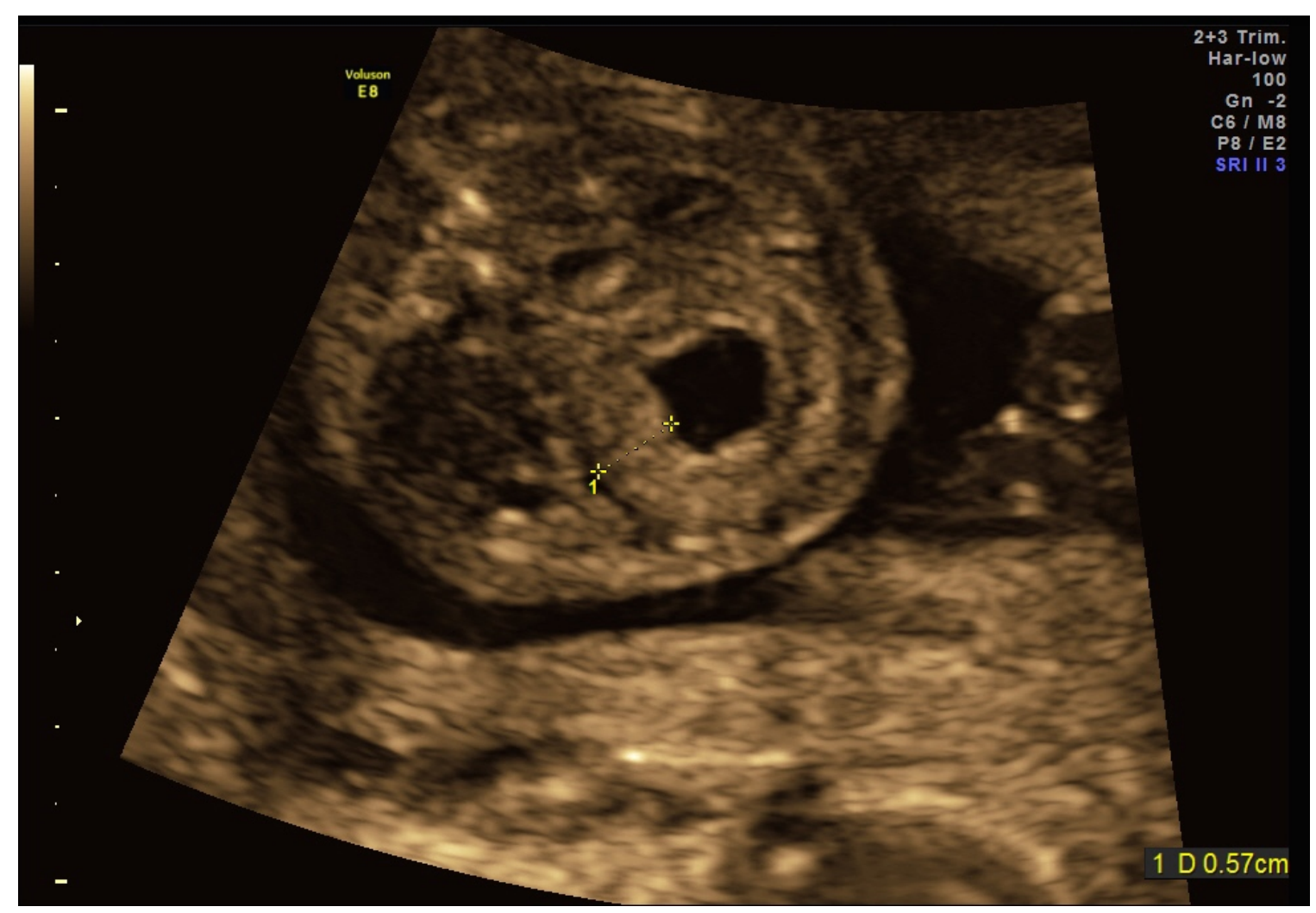

Fig. (5). Thickened bladder wall following vesicocentesis in a 20 -week fetus.

Although a "keyhole" bladder is generally considered to be a specific finding suggestive of PUV, a recent review of 42 fetuses indicated that "keyhole" bladder has 94\% sensitivity, but only $43 \%$ sensitivity for the postnatal diagnosis of PUV [31]. In cases erroneously diagnosed with PUV in the setting of a "keyhole" bladder, the most common postnatal diagnosis was vesicoureteral reflux in $50 \%$ of misdiagnosed cases. Thick-walled bladder and dilated bladder were each significantly associated with a PUV diagnosis, yet each also possessed a substantial false-positive rate as a predictor of PUV. In another study comparing antenatal sonographic findings to postmortem findings in a series of 22 pregnancies with sonographic evidence of LUTO undergoing termination, a "keyhole" bladder was more likely to be associated with urethral atresia [54.5\%] than posterior urethral valves [40.9\%] [32].

An enlarged bladder that is thin-walled and lacking a "keyhole" appearance may support a functional, as opposed to mechanical, obstruction in a suspected LUTO presentation. For example, the characteristic appearance in cases of MMIHS is a large, atonic bladder with a thin wall that progressively enlarges throughout pregnancy [33-35]. Careful inspection of the fetal bladder and urethra is therefore important to exclude atypical causes of LUTO, such as a prolapsed ureterocele. This condition may present with a fetal pelvic or perineal cystic mass in the setting of other findings consistent with an obstructive uropathy.

Other findings in fetuses with LUTO are manifestations of high intravesical pressure, and usually include the presence of hydroureter and renal abnormalities. These findings are not consistently present in all LUTO cases, and the absence of some findings does not necessarily signify a more favorable prognosis. Renal abnormalities include the presence of some or all of caliectasis, hydronephrosis, increased echogenicity within the renal parenchyma, and subcortical cysts (Fig. 6). Findings are not always bilateral, and disproportionate unilateral renal or ureteral involvement can be observed. Severe cases may simply present with small, diffusely echogenic kidneys without caliectasis or hydronephrosis. These latter cases may present with minimally dilated bladders and oligohydramnios, indicative of severe renal dysplasia.

Along with a "keyhole" bladder and renal abnormalities, oligo- or anhydramnios strongly suggests the diagnosis of LUTO [4]. Amniotic fluid volume in early pregnancy is comprised of fetal urine [approximately $10 \mathrm{cc} / \mathrm{kg} / \mathrm{hr}$ ], lung fluid, and early transudation across fetal skin and placenta [36]. As gestation advances through the second trimester, urinary contributions increase proportionate to fetal size while transudative contributions decrease due to progressive keratinization of the fetal skin [36, 37]. By approximately 18 weeks of gestation, amniotic fluid is largely comprised of fetal urine. Therefore, while suspected early second trimester LUTO presentations may not possess oligohydramnios, serial sonographic surveillance is recommended as this can rapidly change with time.

Sonographic assessment of the external genitalia is critical in the evaluation of a suspected antenatal LUTO to exclude abnormal female genitalia and assess the phenotypic normalcy of male genitalia. Congenital megalourethra is diagnosed by a dilated, elongated penis (Fig. 7) [13]. When severe oligohydramnios are present, amnioinfusion can be utilized to confirm a suspected diagnosis. Alternatively, color Doppler study can be used to distinguish a dilated 


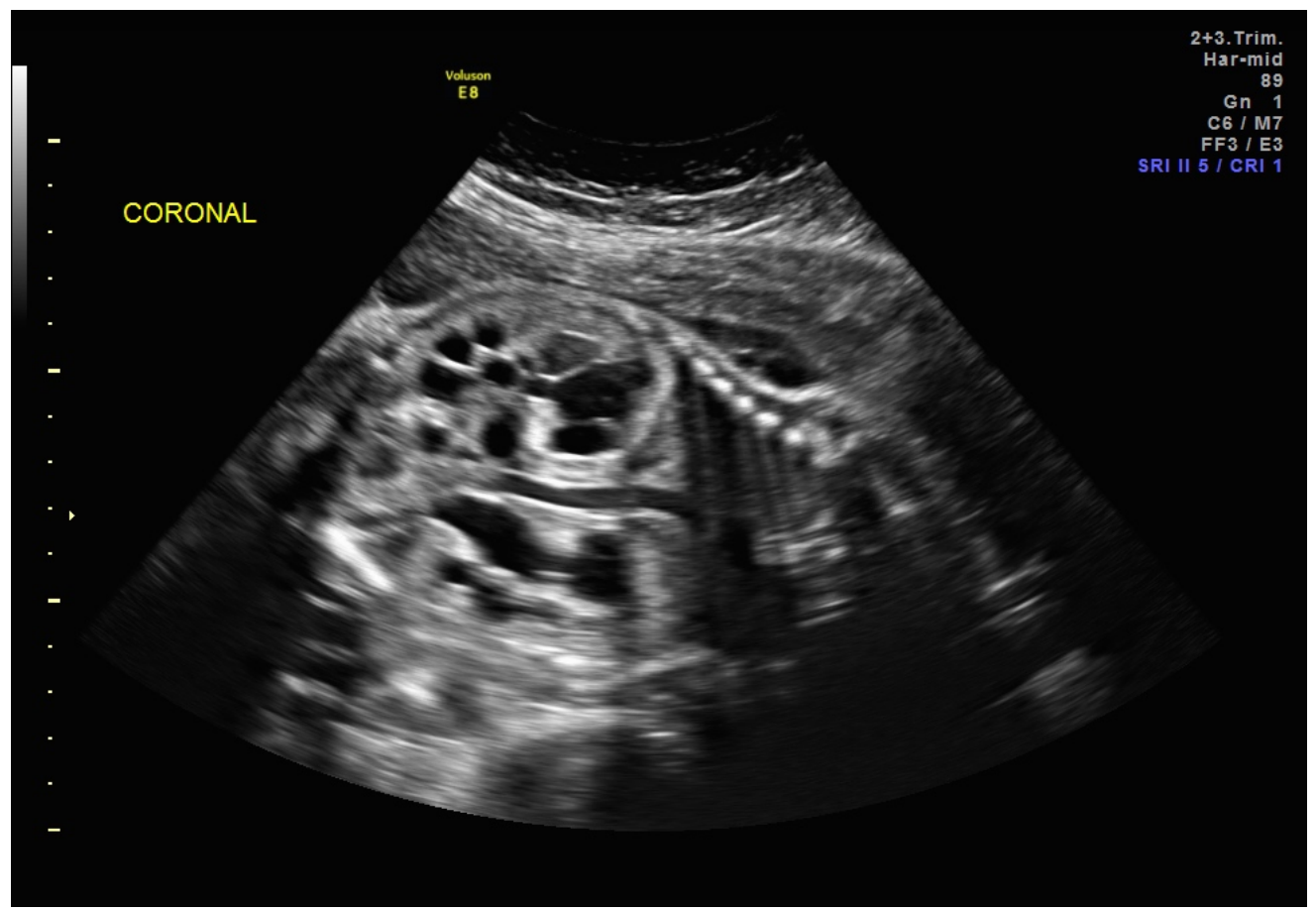

Fig. (6). Dysplastic kidneys in a 30-week fetus with LUTO.

penis from umbilical cord vessels. Megalourethra is usually identified in the second trimester, although it has been diagnosed as early as 12 to 13 weeks $[38,39]$. Fetoscopy has been proposed for diagnosis and distinction between the fusiform and scaphoid forms of megalourethra [15].
Beyond assessment of the genitourinary tract, sonographic assessment of the abdominal cavity is important when evaluating a fetus with suspected LUTO. Dilated stomach or bowel loops are noted in approximately onequarter of cases of MMIHS, and such a finding would raise

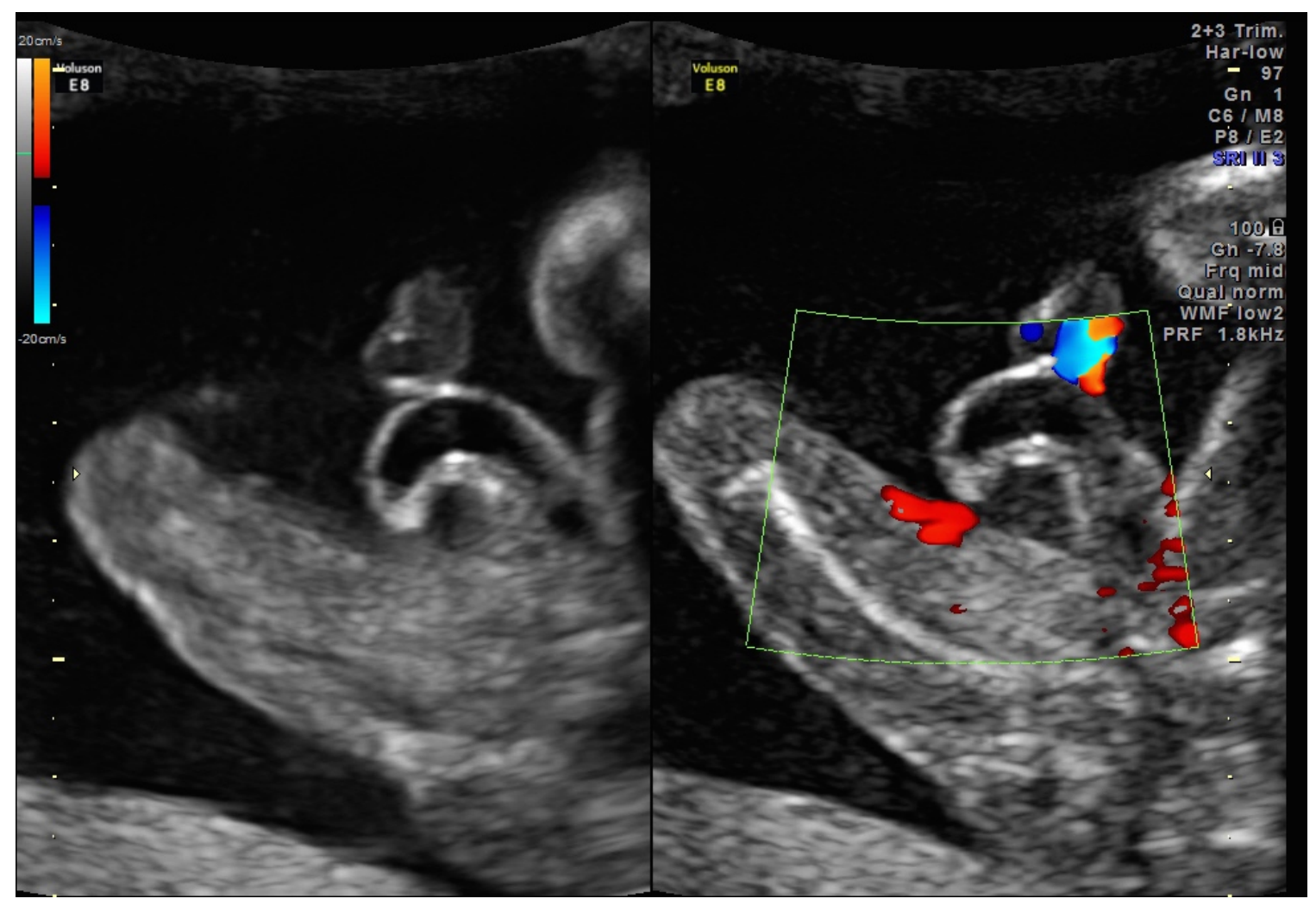

Fig. (7). Congenital megalourethra in a 19-week fetus. Color Doppler imaging [right panel] distinguishes external genitalia from umbilical vessels. 


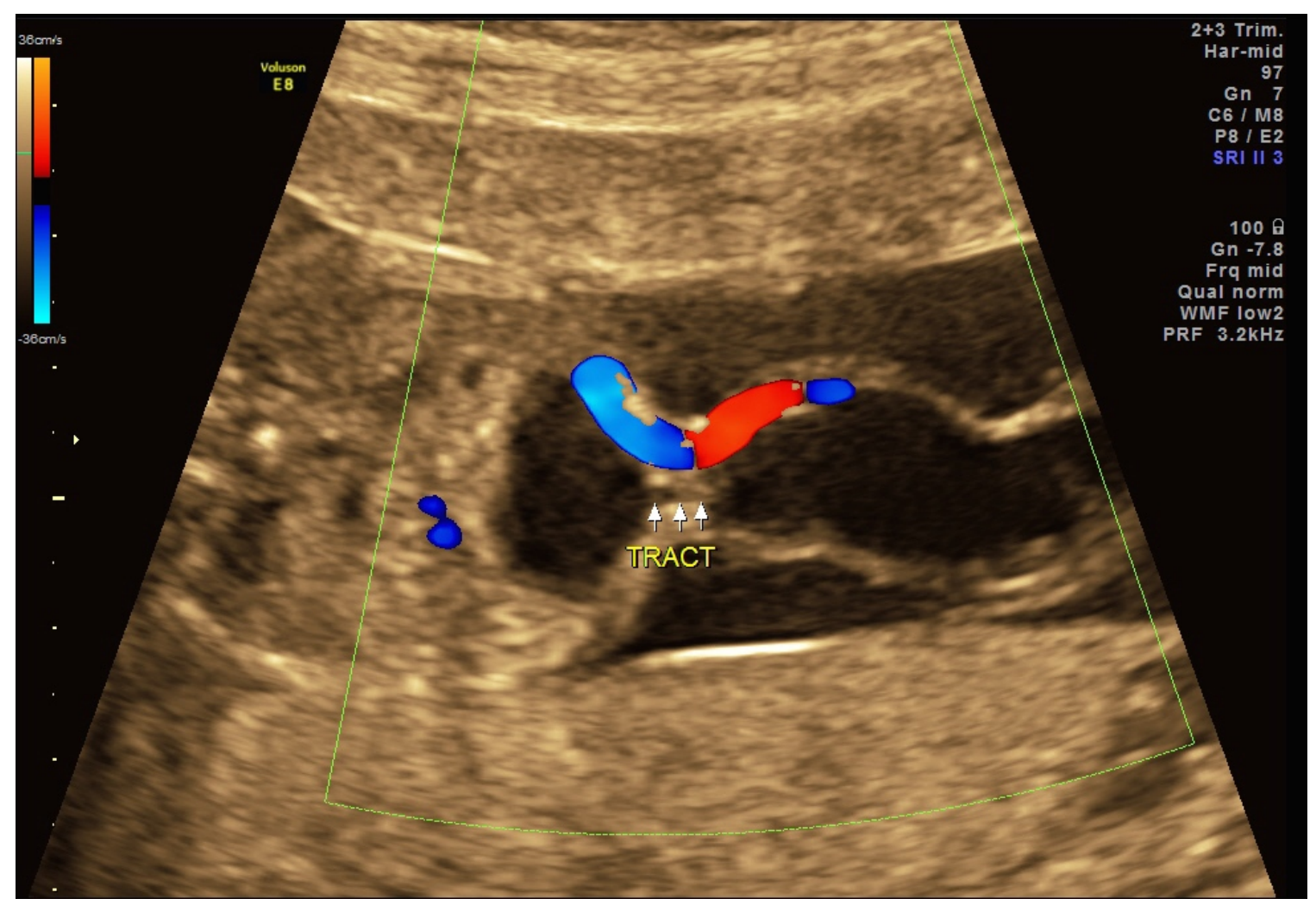

Fig. (8). Patent urachua with associated allantoic cyst in a 17-week fetus. This fetus possesses a single umbilical artery.

suspicion for this underlying diagnosis in the setting of megacystis, and especially when a "keyhole" bladder is not evident [12]. Unfortunately, in cases involving a massively dilated bladder, sonographic assessment of the gastrointestinal tract can be rather limited.

Urinary ascites is another antenatal finding present in some LUTO presentations, usually representing rupture along the urinary tract or related to a perinephric urinoma [22]. Lastly, a communication of the anterior bladder with a cystic dilation within the abdominal wall insertion of the umbilical cord may represent a patent urachus with associated allantoic cyst (Fig. 8) [40]. When present, this rare finding may serve as a "pop-off" mechanism limiting high pressure within the genitourinary system, and therefore may be associated with a more favorable prognosis [41].

Fetal skeletal evaluation is also crucial to the comprehensive assessment of a possible LUTO presentation, although such investigation may be limited by oligohydramnios. Long-standing oligohydramnios may result in limb deformities and scoliosis, however these diagnoses are difficult to secure prenatally. Caudal regression syndrome should also be eliminated from consideration. This condition can result in a dilated neurogenic bladder, and is diagnosed through recognition of a hypoplastic or absent lumbosacral spine along with characteristic limb-position deformities.

Despite its seemingly characteristic presentation, false positive diagnoses are not uncommon in pregnancies with suspected fetal LUTO diagnoses. In the previously cited West Midlands population-based study, 53 of 197 cases [26.9\%] with prenatal LUTO suspicion were ultimately false-positive diagnoses [8]. Of these, 38 cases [71.7\%] possessed bladder findings, including enlarged bladder [ 25 cases], thick-walled bladder [21 cases], and "keyhole" bladder [8 cases]. Common postnatal pathologies among false positive diagnoses included vesicoureteral reflux [24.5\%], cloacal dystrophy [18.9\%], and hydronephrosis [11.3\%]. $20.8 \%$ of false-positive cases were normal at delivery.

\section{FURTHER EVALUATION}

Beyond its obvious role in LUTO diagnosis, prenatal ultrasound is limited in its ability to determine disease severity on a case-by-case basis [42]. Based upon a systematic literature review of published experiences with antenatal LUTO diagnoses, Morris and colleagues concluded that oligohydramnios and renal cortex appearance upon LUTO diagnosis possess moderate predictive accuracy for the postnatal findings of poor renal function [defined as serum creatinine $1.2 \mathrm{mg} / \mathrm{dL}$ ] [43]. The authors reported sensitivities of $63 \%$ and $57 \%$ and specificities of $76 \%$ and $84 \%$ for oligohydramnios and abnormal renal cortical appearance, respectively. However, this review was limited by lack of standardized definitions for key terms such as oligohydramnios among qualifying studies. Zaccara similarly observed some correlation between oligohydramnios and renal function within the first year of life [44]. Robyr additionally suggested that renal echogenicity correlated with renal dysplasia in pregnancies undergoing pathological evaluation after termination [32].

Due to an unreliable correlation between sonographic fetal renal findings and severity of renal dysplasia, 
ultrasound-guided vesicocentesis is commonly used to further analyze fetal renal function in LUTO cases. Fetal urine is a hypotonic ultrafiltrate of fetal serum that becomes progressively more hypotonic with advancing gestational age until the mid-third trimester [45, 46]. This hypotonicity is mediated by resorption at the level of the proximal tubules, which can be damaged by high pressure due to outlet obstruction. The result of this injury is impaired resorption and resultant fetal urine that is relatively hypertonic for gestational age.

A series of up to three vesicocenteses [spaced roughly 48 hours apart] have been proposed to analyze the fetal urine [47]. While one vesicocentesis may suffice if the analyte profile is favorable, there is concern that the first vesicocentesis will analyze stagnant urine that has accumulated over a lengthy time period [48]. Therefore, serial vesicocenteses are believed to provide a more accurate representation of current renal function. Vesicocentesis can be performed with a 22- or 20-gaugle needle (Figs. 9, 10) Due to the aforementioned risk of aneuploidy in LUTO cases, karyotype is also recommended at the time of invasive fetal diagnostic testing. At the time of vesicocentesis, an amnioinfusion may also be performed to improve visualization of the fetal anatomy, and especially the external genitalia.

While the most accurate isolated urinary analytes for prediction of postnatal renal sodium $>95 \%$ for gestational age, no single fetal urinary measure predicts postnatal renal function with acceptable accuracy to be used as an exclusive test [49]. Instead, an overall urinary profile pattern suggestive of preserved renal function may be advisable prior to considering fetal therapy. Widely recommended cut- offs for analyte concentrations based upon historical literature include: sodium $<100 \mathrm{mg} / \mathrm{dL}$, calcium $<8 \mathrm{mg} / \mathrm{dL}$, chloride $<90 \mathrm{mg} / \mathrm{dL}$, osmolality $<200 \mathrm{mOsm} / \mathrm{L}$, total protein $<40 \mathrm{mg} / \mathrm{dL}$, and beta-2 microglobulin $<4 \mathrm{mg} / \mathrm{dL}$; these threshold are at best moderately successful in stratifying cases based upon whether they have sufficiently preserved renal function to be considered for shunt therapy [49-51].

Other proposed evaluations of the fetal kidneys include fetal blood sampling via cordocentesis to determine serum beta- 2 microglobin concentrations and fetal renal biopsy [52, 53]. These approaches have not gained widespread acceptance due to their invasive nature and lack of any evidence indicating superiority to conventional sonographic assessment and urinary sampling [45]. Additionally, there is a high rate of failure to obtain an adequate sample with fetal renal biopsies.

\section{FETAL THERAPY}

The most commonly employed fetal intervention for the treatment of antenatal LUTO presentations is percutaneous vesicoamniotic shunting. Vesicoamniotic shunt therapy serves to bypass the anatomical urinary obstruction, thereby decompressing the fetal bladder and reconstituting the amniotic space (Fig. 11). When performed sufficiently early in the second trimester, shunt therapy may allow for pulmonary development, avoiding pulmonary hypoplasia that can limit or altogether preclude ex utero survival. While theoretically this intervention should also have favorable effect upon the kidneys and urinary tract system, similar benefit is unproven, suggesting perhaps that irreversible insult may have already occurred prior to shunt placement.

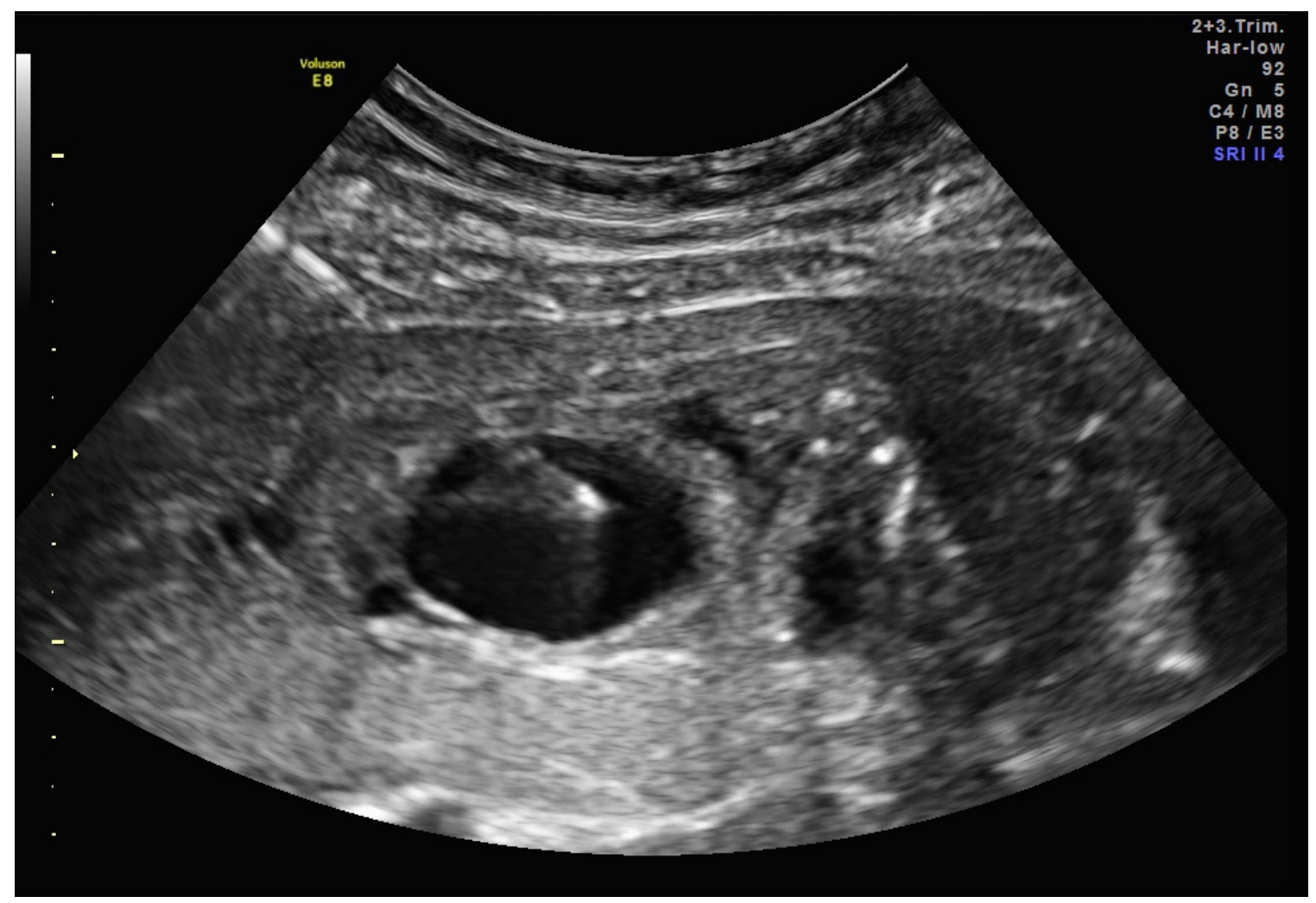

Fig. (9). Vesicocentesis in a 21-week fetus. 


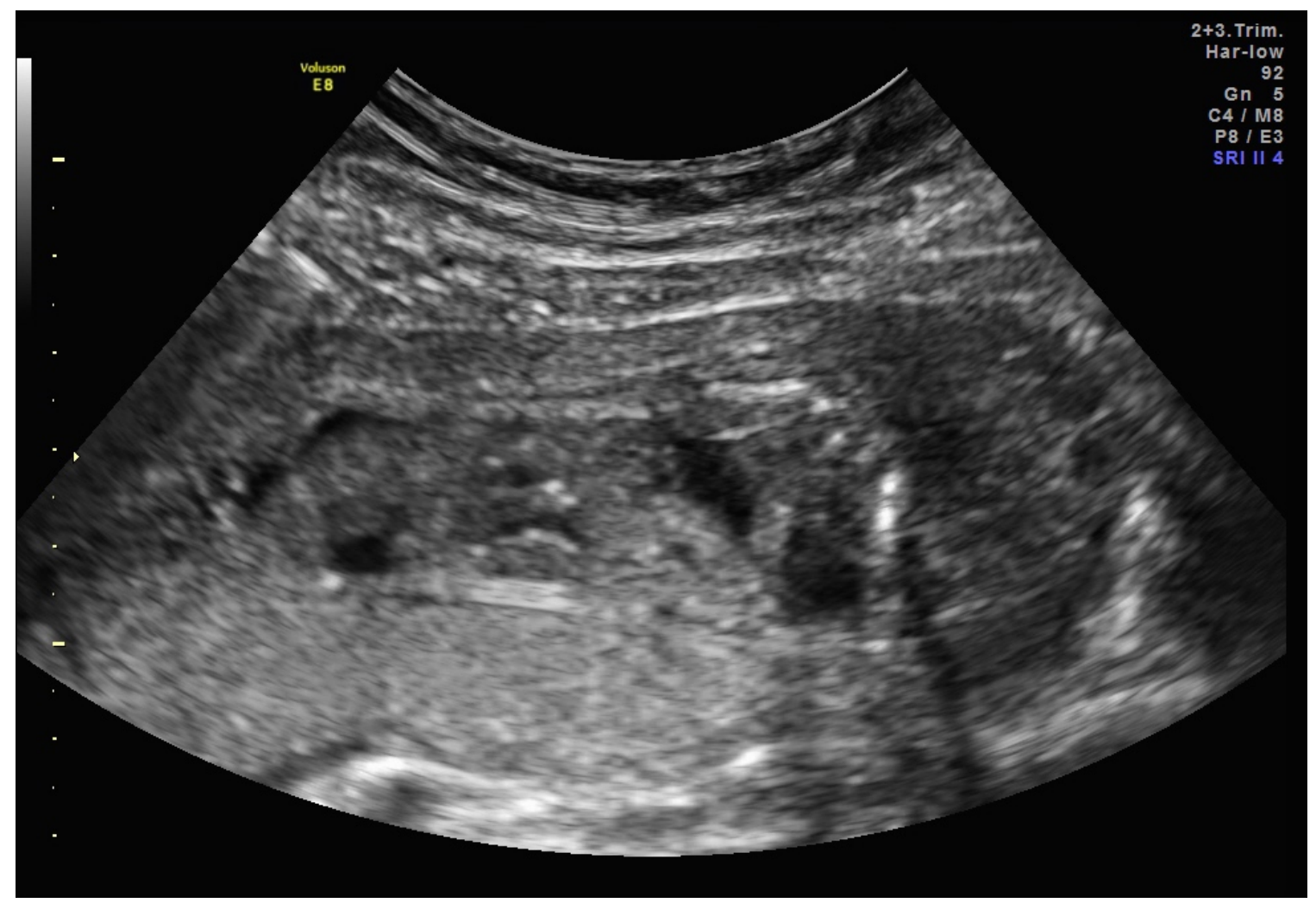

Fig. (10). Completion of vesicocentesis in the same 21-week fetus as Fig. (9), demonstrating a completely decompressed bladder.

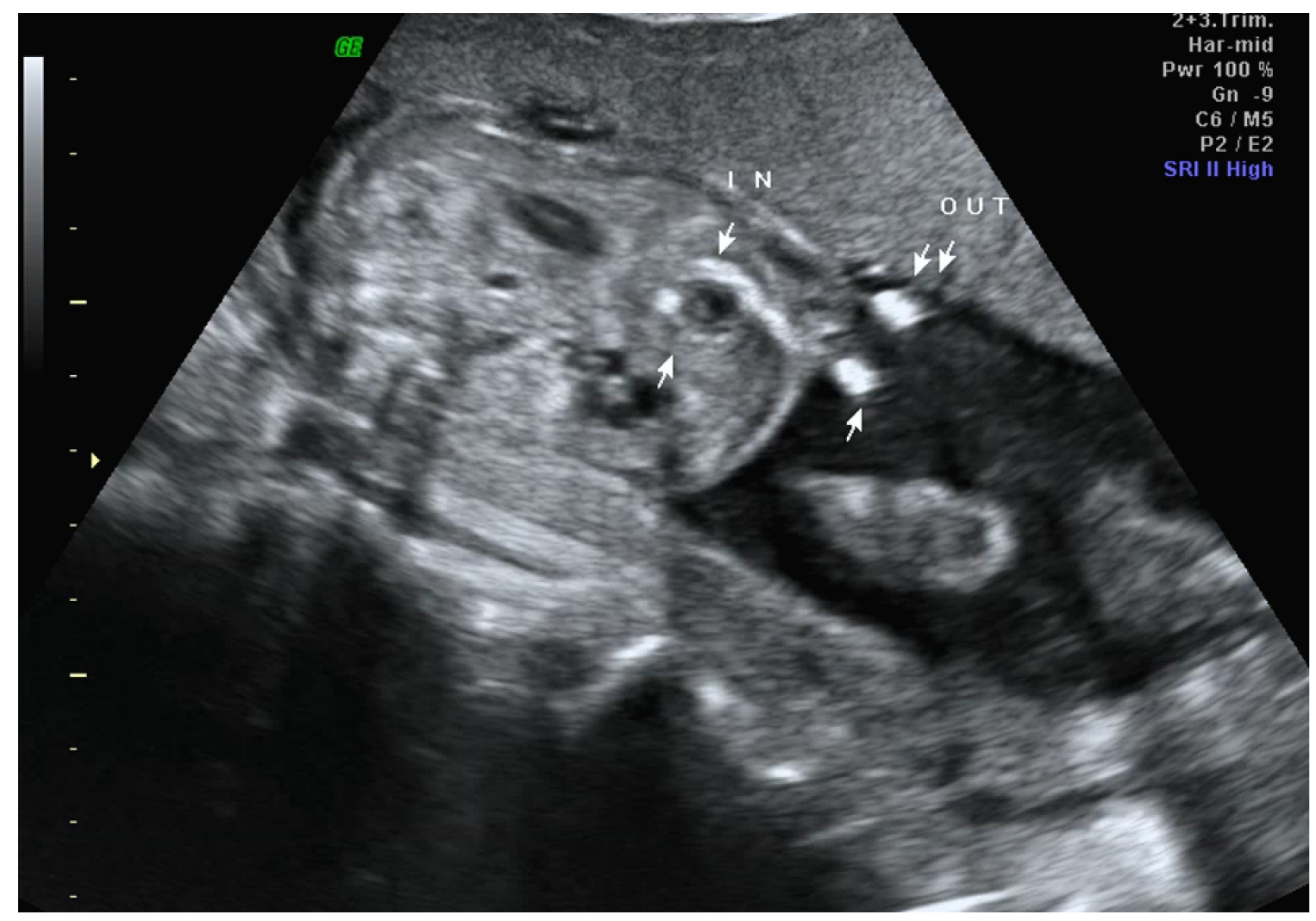

Fig. (11). Vesicoamniotic shunt [Harrison shunt] within a 24-week fetus. "In" demonstrates proper placement within decompressed fetal bladder. "Out" indicates the external portion of the shunt located within the amniotic space. 
In following diagnosis, the patient should be counseled regarding the sonographic presentation, presumed pathophysiology, and prognosis without therapy. Shunt therapy should be presented to appropriate procedural candidates along with options including expectant observation and pregnancy termination when legally available. Patients considering shunt therapy should be referred to a fetal therapy center for multi-disciplinary consultation with maternal-fetal medicine, pediatric urology, pediatric nephrology, and neonatology specialists. Procedural risks and potential benefits should be detailed, and limitations of therapy summarized, to include inability to accurately predict outcomes after therapy on a case-by-case basis. Shunt risks include premature rupture of membranes [PPROM], preterm labor, bleeding, placental abruption, infection, premature delivery, direct fetal injury, and fetal death. Iatrogenic fetal gastroschisis and vascular injury have been described as following shunt placement. Vesicoamniotic shunts are at substantial risk to migrate, dislodge, or occlude over time [54]. Patients should be counseled regarding the likely need for repeat shunting. Counseling must highlight that therapy will not cure the underlying etiology, and that substantial morbidity is the general expectation following successful shunting. Patients should be informed that there may be a major difference between short-term measures of therapeutic success as reported by interventionalists and long-term measures of pediatric health as observed by parents.

Candidates for vesicoamniotic shunt therapy should possess antenatal sonographic findings consistent with a fetal LUTO presentation and oligo- or anhydramnios. Shunt placement in the setting of preserved amniotic fluid volume is a controversial practice. Given data suggests that the most important, if not the only benefit to shunt therapy is its ability to prevent pulmonary hypoplasia. It is unclear whether shunting will help preserve normal lung development. In LUTO presentations with preserved amniotic fluid volume, vigilant sonographic surveillance is recommended on a weekly basis in the mid-trimester for the development of oligohydramnios.

Vesicoamniotic shunts are flexible plastic twin-pigtail catheters. The two most commonly used types are the Rocket [Rocket KCH Fetal Bladder Drain; Rocket Medical, Hingham, MA] and Harrison [Harrison Fetal Bladder Stent Set; Cook Medical Inc., Bloomington, IN] shunts. The Harrison shunt [1.7-mm diameter] is narrower than the Rocket [2.1-mm diameter], allowing it to be introduced through a narrower introducer [2.4-mm diameter versus 3.0 $\mathrm{mm}]$. However, theoretical gains attributable to smaller introducer gauge [such as reduced PPROM risk, reduced fetal injury potential] may be offset by greater chance of occlusion and dislodgement with a narrower shunt, thereby increasing risk for repeat shunt placements. No robust data are available indicating superiority of one shunt type over the other.

Prior to shunt placement, antibiotic prophylaxis is recommended. In our institution, Tylenol \#3 or Percocet are recommended prior to shunt placement, and are used in addition to local $1 \%$ lidocaine infiltration along the intended maternal approach to the fetal target site. Although step-bystep instructions for shunt placement are beyond the scope of this chapter, the goal is to enter the fetal abdomen between the abdominal wall cord insertion and the symphysis pubis, just lateral to the midline, to achieve optimal shunt placement. In the setting of severe oligohydramnios or anhydramnios, amnioinfusion may first be required to enable proper shunt deployment.

It is a challenge to attempt assessing outcomes following vesicoamniotic shunt therapy, since publications are largely restricted to small series of questionable methodological quality. In 2003, Clark and colleagues published a systematic review and meta-analysis of prenatal bladder drainage [defined as vesicocentesis, vesicoamniotic shunt placement, or open fetal bladder surgery] that collected 16 observational studies and 342 total LUTO cases [55]. Overall perinatal survival in the included series ranged from $0 \%$ to $100 \%$, with the same survivorship range when data were restricted to those cases undergoing vesicoamniotic shunt placement. Meta-analysis revealed statistically significant improvement in perinatal survival with prenatal intervention compared to no intervention [Odds Ratio 2.5, 95\% CI 1.1-5.9; $\mathrm{p}=0.03$ ]. Proportions of survivors with "normal" renal function were no different among these groups. Survivorship benefit with therapy appeared to have been largely driven by marked improvement among fetuses with a "poor" predicted prognosis prior to shunting [Odds Rayio 8., 95\% CI 1.252.9; $\mathrm{p}=0.03]$. Similar survival benefit could not be demonstrated among fetuses with a "good" predicted prognosis. Despite a potential survival benefit within the subset of patients with "poor" predicted prognoses upon urinary analyte analysis, shunt therapy is generally discouraged within this group due to concern for severe renal and other genitourinary morbidity after birth.

With regard to long-term outcomes among survivors, Biard and colleagues reported on clinical outcomes in 20 pregnancies involving shunt therapy for fetal LUTO, with a mean age at follow-up of 5.8 years [56]. Two neonates died from pulmonary hypoplasia, leaving 18 children in the living cohort. While eight children had acceptable renal function [defined as creatinine clearance $>70 \mathrm{~mL} / \mathrm{min}$ ], six survivors required dialysis and eventual transplantation, and four possessed mild renal insufficiency. Six children required catheterization and one had a vesicostomy. Musculoskeletal and respiratory problems were common within this cohort. Interestingly, when children within this LUTO cohort selfreported their health-related quality of life, it was comparable to that reported by a healthy reference pediatric population.

In 2013, Morris and colleagues published the results of the PLUTO randomized trial [57]. This multi-center European trial recruited informed women with singleton male fetuses with sonographic LUTO diagnoses, without consideration for amniotic fluid volume, randomization to vesicoamniotic shunt placement or conservative management. The primary outcome measure was survival to 28 days after birth, with secondary outcomes including longer-term survival and renal function measures. Although the planned sample size for the trial was 150 subjects, it was prematurely discontinued at 31 subjects [16 randomized to shunting, 15 to conservative management] due to recruitment difficulties. There was no significant survival benefit upon intention-to-treat analysis, with eight $[50 \%]$ neonates 
randomized to shunting and four [26.7\%] randomized to conservative management surviving to 28 days [RR 1.88 , $95 \%$ CI 0.71-4.96; $\mathrm{p}=0.27]$. However, when analysis was conducted, based upon treatment receiving there was a significant early survival benefit to shunting [RR 3.2, 95\% CI 1.06-9.62; $\mathrm{p}=0.03$ ]. Likelihood of survival with normal renal function was very low in both groups, although two survivors in the shunt group possessed normal renal function at two years of age. $46.7 \%$ of shunt placements were complicated by PPROM, dislodgement, or occlusion. Overall, the authors concluded that while shunting may provide some degree of survival benefit, prospects of normal renal function appeared to be low with or without therapy. A related publication by the PLUTO research group further indicted that vesicoamniotic shunt therapy unlikely to be a cost-effective intervention [58].

Vesicostomy or bilateral uretreostomy via open fetal surgery, fetal cystoscopy, and fetal transurethral stenting have all been attempted in the treatment of antenatal LUTO with mixed success, with current use limited to care at selective fetal therapy centers [59-63]. Outcomes from case reports and small series do not demonstrate sufficient benefit to any of these alternative therapies such that any thing should be recommended over less invasive percutaneous vesicoamniotic shunt placement.

\section{CONCLUSION}

Fetal lower urinary tract obstruction [LUTO] represents a rare, heterogeneous group of uropathies involving mechanical or functional blockage at the bladder outlet of varying severity. While ultrasound is a fair screening tool for the antenatal detection of this condition, it cannot reliably determine the underlying etiology of LUTO presentations. Sonographic assessment of renal appearance and amniotic fluid volume, as well as urinary analyte analysis, are the most useful predictors of preserved renal function in fetal LUTO.They, too, are limited in their ability to predict outcomes on an individual basis. Animal models suggest that obstructive uropathy likely causes irreparable damage to the renal and urinary collecting system injury in early in pregnancy. When LUTO is associated with abnormal amniotic fluid volume, long-standing oligohydramnios may result in lethal pulmonary hypoplasia. Data evaluating the efficacy of vesicoamniotic shunt therapy for the treatment of fetal LUTO are inconclusive, with recent randomized controlled trials discontinued early due to poor recruitment. While vesicoamniotic shunting may modify disease lethality by restoring fluid volume, renal and other genitourinary benefits are minimal if not altogether absent, arguably supporting the belief that bladder decompression is being performed after irreversible injury has already been sustained.

\section{ABBREVIATIONS}

$\mathrm{ESRD}=$ End stage renal disease

LUTO $=$ Lower urinary tract obstruction

MMIHS = Megacystis megacolon intestinal hypoperistalsis syndrome
PPROM $=$ Premature rupture of membranes

PUV $=$ Posterior urethral valves

\section{CONFLICT OF INTEREST}

The author confirms that this article content has no conflict of interest.

\section{ACKNOWLEDGEMENTS}

Declared none.

\section{REFERENCES}

[1] Atwell JD. Posterior urethral valves in the British Isles: a multicenter B.A.P.S. review. J Paediatr Surg 1983; 18: 70-4.

[2] Dinneen MD, Duffy PG. Posterior urethral valves. Br J Urol 1996; 78: $275-81$

[3] Anumba DO, Scott JE, Plant ND, et al. Diagnosis and outcome of fetal lower urinary tract obstruction in the northern region of England. Prenat Diagn 2005; 25: 7-13.

[4] Nguyen HT, Herndon CD, Cooper C, et al. The society for fetal urology consensus statement on the evaluation and management of antenatal hydronephrosis. J Pediatr Urol 2010; 6: 212-31.

[5] Thomas DF, Gordon AC. Management of prenatally diagnosed uropathies. Arch Dis Child 1989; 64: 58-63.

[6] Mallik M, Watson AR. Antenatally detected urinary tract abnormalities: more detection but less action. Pediatr Nephrol 2008; 23: 897-904.

[7] Richmond S, Atkins J. A population-based study of the prenatal diagnosis of congenital malformation over 16 years. BJOG 2005; 112: 1349-57.

[8] Malin G, Tonks AM, Morris RK, et al. Congenital lower urinary tract obstruction: a population-based epidemiological study. BJOG 2012; 119: 1455-64.

[9] Young HH, Frontz WA, Baldwin JC. Congenital obstruction of the posterior urethra. J Urol 1919; 3: 289-365.

[10] Hassett S, Smith GH, Holland AJ. Prune belly syndrome. Pediatr Surg Int 2012; 28: 219-28.

[11] Tonni G, Ida V, Alessandro V, et al. Prune-belly syndrome: case series and review of the literature regarding early prenatal diagnosis, epidemiology, genetic factors, treatment, and prognosis. Fetal Pediatr Pathol 2013; 31: 13-24.

[12] Tuzovic L, Anyane-Yeboa K, Mills A, et al. Megacystismicrocolon-intestinal hypoperistalsis syndrome: case report and review of prenatal ultrasonographic findings. Fetal Diagn Ther 2014; 36: 74-80.

[13] Amsalem H, Fitzgerald B, Keating S, et al. Congenital megalourethra: prenatal diagnosis and postnatal/autopsy findings in 10 cases. Ultrasound Obstet Gynecol 2011; 37: 678-83.

[14] Jones EA, Freedman AL, Ehrlich RM. Megalourethra and urethral diverticula. Urol Clin N Am 2002; 29: 341-8.

[15] Yamamoto R, Ishii K, Ukita S, et al. Fetoscopic diagnosis of congenital megalourethra at early second trimester. Fetal Diagn Ther 2013; 34: 63-5.

[16] Sepulveda W, Elorza C, Gutierrez J, et al. Congenital megalourethra: outcome after prenatal diagnosis in a series of 4 cases. J Ultras Med 2005; 24: 1303-8.

[17] Mann S, Johnson MP, Wilson RD. Fetal thoracic and bladder shunts. Semin Fetal Neonatal Med 2010; 15: 28-33.

[18] Manning FA, Harrison MR, Rodeck C. Catheter shunts for fetal hydronephrosis and hydrocephalus. Report of the International Fetal Surgery Registry. N Engl J Med 1986; 315: 336-40.

[19] Crombleholme TM, Harrison MR, Golbus MS, et al. Fetal intervention in obstructive uropathy: prognostic indicators and efficacy of intervention. AJOG 1990; 162: 1239-44.

[20] Cusick EL, Didier F, Droulle P, et al. Mortality after an antenatal diagnosis of foetal uropathy. J Pediatr Surg 1995; 30: 463-6.

[21] Nakayama DK, Harrison MR, de Lorimier AA. Prognosis of posterior urethral valves presenting at birth. J Pediatr Surg 1986; 21: 43-5. 
[22] Mahony BS, Callen PW, Filly RA. Fetal urethral obstruction: US evaluation. Radiology 1985; 157: 221-4.

[23] Heikkila J, Holmberg C, Kyllonen L, et al. Long-term risk of end stage renal disease in patients with posterior urethral valves. $\mathrm{J}$ Urol 2011; 186: 2392-6.

[24] Smith JM, Stablein DM, Munoz R, et al. Contributions of the transplant registry: the 2006 annual report of the north American pediatric renal trials and collaborative studies [NAPRTCS]. Pediatr Transplant 2007; 11: 366-73.

[25] Taskinen S, Heikkila J, Rintala R. Effects of posterior urethral valves on long- term bladder and sexual function. Nat Rev Urol 2012; 9: 699-706.

[26] Kitagawa H, Pringle KC, Koike J, et al. The early effects of urinary tract obstruction on glomerulogenesis. J Pediatr Surg 2004; 39: 1845-8.

[27] Kitagawa H, Pringle KC, Koike J, et al. Vesicoamniotic shunt for complete urinary tract obstruction is partially effective. J Pediatr Surg 2006; 41: 394-402.

[28] Kitajima K, Aoba T, Pringle KC, et al. Bladder development following bladder outlet obstruction in fetal lambs: optimal timing of fetal therapy. J Pediatr Surg 2010; 45: 2423-30.

[29] Nyirady P, Cuckow PM, Fry CH. Changes to the contractile function of ureter smooth muscle after partial infravesical obstruction in fetal sheep. BJU Int 2008; 102: 490-4.

[30] Wiesel A, Queisser-Luft A, Clementi M, et al. Prenatal detection of congenital renal malformations by fetal ultrasonographic examination: an analysis of 709,030 births in 12 European countries. Eur J Med Genet 2005; 48: 131-44.

[31] Bernardes LS, Aksnes G, Saada J, et al. Keyhole sign: how specific is it for the diagnosis of posterior urethral valves? Ultrasound Obstet Gynecol 2009; 34: 419-23.

[32] Robyr R, Benachi A, Daikha-Dahmane F, et al. Correlation between ultrasound and anatomical findings in fetuses with lower urinary tract obstruction in the first half of pregnancy. Ultrasound Obstet Gynecol 2005; 25: 478-82.

[33] Witters I, Theyskens C, van Hoestenberghe R, et al. Prenatal diagnosis of non-obstructive megacystis as part of the megacystismicrocolon-intestinal hypoperistalsis syndrome with favourable postnatal outcome. Prenat Diagn 2001; 21: 704-6.

[34] Bornstein E, Atkins K, Fishman S, et al. Severe uropathy and normal amniotic fluid volume in a male fetus: sonographic surveillance leading to the diagnosis of megacystis-microcolonintestinal hypoperistalsis syndrome. J Ultras Med 2008; 27: 1099104.

[35] Hidaka N, Kawamata K, Chiba Y. Megacystis-microcolonintestinal hypoperistalsis syndrome: in utero sonographic appearance and the contribution of vesicocentesis in antenatal diagnosis. J Ultrasound Med 2006; 25: 765-9.

[36] Harman CR. Amniotic fluid abnormalities. Semin Perinatol 2008; 32: 288-94.

[37] Underwood MA, Gilbert WM, Sherman MP. Amniotic fluid: not just fetal urine anymore. J Perinatol 2005; 25: 341-8.

[38] Lam YH, Tang MH. Sonographic diagnosis of congenital megalourethra at 13 weeks of gestation. Ultrasound Obstet Gynecol 2000; 16: 585-6.

[39] Krapp M, Geipel A, Germer U, et al. First-trimester sonographic diagnosis of distal urethral atresia with megalourethra in VACTERL association. Prenat Diagn 2002; 22: 422-4.

[40] Gupta N, Corbett H, Ismail R, et al. Allantoic cyst - an unusual umbilical cord swelling. J Surg Case Rep 2011; 2011: 5.

[41] Kaefer M, Keating MA, Adams MC, et al. Posterior urethral valves, pressure pop-offs and bladder function. J Urol 1995; 154 : 708-11.

[42] Bernardes LS, Salomon R, Aksnes G, et al. Ultrasound evaluation of prognosis in fetuses with posterior urethral valves. J Pediatr Surg 2011; 46: 1412-8.

[43] Morris RK, Malin GL, Khan KS, et al. Antenatal ultrasound to predict postnatal renal function in congenital lower urinary tract obstruction: systematic review of test accuracy. BJOG 2009; 116 : 1290-9.

[44] Zaccara A, Giorlandino C, Mobili L, et al. Amniotic fluid index and fetal bladder outlet obstruction. Do we really need more? J Urol 2005; 174: 1657-60.

[45] Nicolini U, Spelzini F. Invasive assessment of fetal renal abnormalities: urinalysis, fetal blood sampling and biopsy. Prenat Diagn 2001; 21: 964-9.

[46] Nicolini U, Fisk NM, Rodeck $\mathrm{CH}$, et al. Fetal urine biochemistry: an index of renal maturation and dysfunction. BJOG 1992; 99: 4650 .

[47] Johnson MP, Corsi P, Bradfield W, et al. Sequential urinalysis improves evaluation of fetal renal function in obstructive uropathy. Am J Obstet Gynecol 1995; 173: 59-65.

[48] Nicolini U, Tannirandorn Y, Vaughan J, et al. Further predictors of renal dysplasia in fetal obstructive uropathy: bladder pressure and biochemistry of 'fresh' urine. Prenat Diagn 1991; 11: 159-66.

[49] Morris RK, Quinlan-Jones E, Kilby MD, et al. Systematic review of accuracy of fetal urine analysis to predict poor postnatal renal function in cases of congenital urinary tract obstruction. Prenat Diagn 2007; 27: 900-11.

[50] Grannum PA, Ghidini A, Scioscia A, et al. Assessment of fetal renal reserve in low level obstructive uropathy. Lancet 1989; 1(8632): 281-2.

[51] Johnson MP, Bukowski TP, Reitleman C, et al. In utero surgical treatment of fetal obstructive uropathy: a new comprehensive approach to identify appropriate candidates for vesicoamniotic shunt therapy. Am J Obstet Gynecol 1994; 170: 1770-6; discussion.

[52] Berry SM, Lecolier B, Smith RS, et al. Predictive value of fetal serum beta 2-microglobulin for neonatal renal function. Lancet 1995; 345(8960): 1277-8.

[53] Bunduki V, Saldanha LB, Sadek L, et al. Fetal renal biopsies in obstructive uropathy: feasibility and clinical correlations preliminary results. Prenat Diagn 1998; 18: 101-9.

[54] Freedman AL, Johnson MP, Gonzalez R. Fetal therapy for obstructive uropathy: past, present future? Pediatr Nephrol 2000; 14: 167-76.

[55] Clark TJ, Martin WL, Divakaran TG, et al. Prenatal bladder drainage in the management of fetal lower urinary tract obstruction: a systematic review and meta-analysis. Obstet Gynecol 2003; 102: 367-82.

[56] Biard JM, Johnson MP, Carr MC, et al. Long-term outcomes in children treated by prenatal vesicoamniotic shunting for lower urinary tract obstruction. Obstet Gynecol 2005; 106: 503-8.

[57] Morris RK, Malin GL, Quinlan-Jones E, et al. Percutaneous vesicoamniotic shunting versus conservative management for fetal lower urinary tract obstruction [PLUTO]: a randomised trial. Lancet 2013; 382(9903): 1496-506.

[58] Morris RK, Malin GL, Quinlan-Jones E, et al. The percutaneous shunting in Lower Urinary Tract Obstruction [PLUTO] study and randomised controlled trial: evaluation of the effectiveness, costeffectiveness and acceptability of percutaneous vesicoamniotic shunting for lower urinary tract obstruction. Health Technol Assess 2013; 17: 1-232.

[59] Lissauer D, Morris RK, Kilby MD. Fetal lower urinary tract obstruction. Semin Fetal Neonatal Med 2007; 12: 464-70.

[60] Agarwal SK, Fisk NM. In utero therapy for lower urinary tract obstruction. Prenat Diagn 2001; 21: 970-6.

[61] Clifton MS, Harrison MR, Ball R, et al. Fetoscopic transuterine release of posterior urethral valves: a new technique. Fetal Diagn Ther 2008; 23: 89-94.

[62] Quintero RA, Hume R, Smith C, et al. Percutaneous fetal cystoscopy and endoscopic fulguration of posterior urethral valves. Am J Obstet Gynecol 1995; 172: 206-9.

[63] Welsh A, Agarwal S, Kumar S, et al. Fetal cystoscopy in the management of fetal obstructive uropathy: experience in a single European centre. Prenat Diagn 2003; 23: 1033-41. 